\title{
La frontera sur de Europa: motivaciones y consecuencias sociopolíticas de la migración ${ }^{1}$
}

José Cazorla

Universidad de Granada

Palabras clave: Migraciones, Globalización, Lugares de Acogida y de Origen, Riesgos, Cultura Tradicional, Desempleo, Frustración, Desigualdades, Autovaloración, Regímenes Islámicos, Racismo.

1 El presente trabajo procede en su versión original inglesa de la Stein Rokkan Lecture 2005, presentada por el autor en la Joint Session del European Consortium for Political Research, en el Aula Magna de la Facultad de Ciencias Políticas y Sociología de la Universidad de Granada, 16 abril 2005, y publicada en la misma fecha. 


\section{INTRODUCCIÓN}

Desde hace algún tiempo, se vienen haciendo diversos intentos para desentrañar algunas claves sociopolíticas de un problema a la vez universal y muy próximo: el de la inmigración. Problema que se presencia y se vive cada día, sobre todo, en las costas españolas de Canarias y el Sur, las cuales vienen recibiendo, especialmente en estos dos últimos años, miles de inmigrantes que cruzan esta parte del Mediterráneo en pequeños botes, con los medios más precarios, en su afán de compartir el nivel europeo de desarrollo. Concretamente en 2004-2005, la provincia de Granada ha sido (salvo Canarias) la española que mayor inmigración alegal por mar ha recibido. Lo más grave es que muchos de sus protagonistas perecen en el intento. Nadie sabe cuántos, pero se especula con cifras próximas a los dos mil desaparecidos.

En el conjunto de nuestro país, en 2003 entraron oficialmente 593.000 inmigrantes, la mayor cifra de toda la Unión Europea (35,3\% del total). Nos siguieron como receptores, por este orden, Italia y Alemania. En forma abreviada, nos referiremos a este fenómeno como parte de un movimiento actual de carácter universal, y con particular referencia al Mediterráneo occidental, subrayando las motivaciones que lo inducen convirtiéndolo en masivo, así como a las consecuencias de orden social y político que de él se derivan. Lo que sí quisiéramos dejar muy explícito desde el principio es que lo que hasta hace poco tiempo se contemplaba como una mera cuestión demográfica, se ha convertido más recientemente en un problema de alcance y consecuencias de trascendencia en absoluto local, ni siquiera regional, sino global, de efectos difícilmente previsibles y especial repercusión política a medio plazo.

\section{LAS MIGRACIONES, COMO FENÓMENO GLOBAL}

La principal diferencia entre las migraciones que llamaríamos «tradicionales» y las actuales radica en que aquéllas se dirigían, por lo general, desde Europa hacia los otros continentes e islas del Pacífico, mientras que en el presente el flujo se ha invertido, orientándose ahora desde la periferia (con población además no occidental) al centro (en el que predomina ésta).

De tal manera que los movimientos migratorios internacionales de hoy en día se caracterizan ante todo por su generalización, puesto que abarcan prácticamente a los cinco continentes, con una importancia hasta ahora desconocida. Ello significa también que sus componentes varían mucho en origen, clase social, modo de acceso al nuevo territorio y diversificación en destino. 
Hay actualmente migraciones de la más diversa índole. Así, la del retorno de los rusos expulsados de muchos de los Estados - hoy independientes - que formaban la antigua URSS, que suman más de dos millones, y que han sido forzados a dejar sus puestos de trabajo en aquéllos y regresar a «su país», para muchos hasta ahora desconocido. En el que, además, tropiezan con toda clase de dificultades para encontrar trabajo, pese a sus generalmente altas cualificaciones profesionales. Igualmente merecen citarse circunstancias inéditas respecto a los movimientos migratorios tradicionales, como los procedentes de China, Sudamérica, Caribe o Filipinas hacia Europa y Estados Unidos, que superan hoy con mucho las distancias y volumen de antiguas migraciones, además de su carácter a menudo clandestino.

La creciente trascendencia política de las migraciones ha hecho que diversas organizaciones internacionales tomen cartas en el asunto. Para citar un solo ejemplo de esta preocupación bastará aludir al nuevo eje estratégico de la OTAN, el cual, según los Acuerdos de Washington de 23 y 24 de abril de 1999, incluye conceptos muy novedosos en materia de seguridad, los cuales los complementan en función de nuevas situaciones. Y, así, se señala que los intereses de la Alianza «pueden verse afectados por riesgos distintos de carácter más general, en particular, actos de terrorismo, de sabotaje o de delincuencia organizada, y por la perturbación del flujo de recursos vitales. Asimismo pueden plantear problemas para la seguridad y la estabilidad que afecten a la Alianza, los grandes movimientos incontrolados de población, en particular los resultantes de conflictos armados». Se definen, pues, nuevos riesgos, antes no conceptuados como tales, pero que es preciso prever y eventualmente solucionar.

Por eso, el desplazamiento inesperado de grandes grupos incontrolados de emigrantes, refugiados políticos, personas sin documentación o huidos de conflictos internos o internacionales, cada vez de mayor volumen y frecuencia, puede afectar seriamente a la seguridad internacional, por lo que la Alianza no se va a considerar ajena a ellos. También debe advertirse que los gobiernos de los países desarrollados cada vez se resisten más a admitir a refugiados e inmigrantes no regularizados.

Los inmigrantes tienden ahora a permanecer de forma permanente en el lugar de destino, dadas las dificultades de desarrollo de sus países y localidades de origen, a los que sólo un cierto número vuelve, en todo caso, de vacaciones. A pesar de lo cual, por lo general, y sobre todo en el caso de los inmigrantes de origen no occidental, cada vez se esfuerzan menos por integrarse en la sociedad a la que llegan. A ello contribuye - como veremosla mencionada variedad y cantidad de sus componentes y un cierto alejamiento respecto a las pautas culturales del lugar de acogida. Este nuevo subproletariado inmigrante es mucho más numeroso y visible que el preexistente y su propósito es más de «acomodación» 
que de integración. Así, por ejemplo, se usa normalmente el idioma original en el ámbito familiar, incluso al cabo de varias generaciones, mientras se usa el local para la comunicación que llamaríamos «exterior». Otro tanto ocurre con ciertos usos y costumbres, incluido el comportamiento político, sobre todo con respecto a las libertades de la mujer en algunas culturas.

No es menos cierto que determinadas conductas imitativas — sobre todo en los jóvenes, como atuendos, actitudes, uso de medios técnicos - han adquirido un rango universal que a la vez tiende a homogeneizarlos. En ese proceso, el papel de los medios de comunicación, y en especial la televisión, es decisivo. La cultura tradicional va quedando atrás al par que la generación correspondiente, que pesa ya mucho menos de lo que en su momento significó para los padres. Esto implica sustituciones de unas pautas por otras, pero también la aparición de «huecos» y «vacíos» en el techo cultural, que la nueva sociedad de acogida no siempre llena, y que a veces se traduce en comportamientos atípicos —o incluso marginales- en los jóvenes de la segunda y tercera generación de inmigrantes.

Los expertos han señalado que las variables que tradicionalmente se consideraban en los países de origen como explicativas de la motivación de emigrar han cambiado profundamente. Así, la presión demográfica y el inevitable alto desempleo, la falta de perspectivas en los jóvenes y la pobreza no bastan por sí solos, hoy, para marcarlos como decisivos a la hora de romper con los lazos afectivos y familiares habituales. Con tanta o mayor fuerza operan factores de atracción en el lugar de destino.

Tal y como hemos señalado en otros momentos, el que calificábamos como «efecto escaparate» de los países desarrollados actúa con mucha mayor eficacia que en cualquier época anterior. Se exhibe a través de los medios un consumismo desbordado, en el que, como hace ya décadas comentó el Presidente de Indonesia, Sukarno, aparentemente cualquier persona accede con toda facilidad a bienes y servicios a los que sólo en sueños se llega en el país de origen. Tal efecto es realmente demoledor, en especial cuando la distancia física es muy reducida — como ocurre a los magrebíes respecto al suroeste de Europa-, reforzado además por la fácil recepción de las emisoras de radio y televisión de la orilla norte del Mediterráneo. La frustración y anomia resultantes de la diferencia entre aquello a lo que se aspira y lo que en realidad se recibe producen frustraciones irresistibles en millones de jóvenes.

A lo que contribuye por demás el observar a menudo cómo un vecino, amigo o pariente regresa para sus vacaciones desde Europa o Estados Unidos con una inevitable exhibición de su recién adquirida capacidad económica, coche, regalos y objetos de consumo. En los años sesenta y setenta tuvimos los españoles una amplia experiencia al respecto, que 
ahora se repite con nuestro país como objeto de deseo. Y es que entre los más básicos móviles de la emigración se encuentra el prestigio relativo, tan importante como la seguridad del empleo o la estabilidad económica. Una función latente, pues, de ese regreso, aunque sea breve, radica en la adquisición de un mejor estatus ante sus compatriotas, que produce una especial satisfacción y autovaloración (Cazorla, 1989)².La absorción de valores característicos de la cultura occidental, sobre todo en los jóvenes (el uso de la libertad individual, la autonomía de las decisiones, la presión del grupo de iguales, el derecho a disentir, el afán de aprender, la innovación, la búsqueda de la satisfacción inmediata y del consumo), es otro factor cuya influencia no puede ignorarse, incluso si se mantienen otras pautas culturales de orden familiar, religioso o tradicional.

En este sentido, es de destacar el peso que sobre el papel político y social de la mujer adquiere en muchos casos la cultura del lugar de destino. Las fuertes restricciones que a su libertad imponen ciertas creencias (musulmanas o de otra clase) provocan a plazo medio - especialmente en las más jóvenes - un creciente repudio resultante de un ambiente en el que el contraste con la mayoría y la autovaloración exigen su modificación drástica. Lo cual conduce a problemas y rechazos familiares cotidianos e inevitables, pero beneficiosos para su autonomía en el mundo en que se encuentran. En efecto, la participación de las mujeres inmigrantes en diversas actividades comunitarias, lúdicas o políticas (no sólo electorales) de los países de acogida es manifiesta y creciente, pese a los obstáculos culturales y tradicionales mencionados.

A menudo, los recién llegados tropiezan a su vez con resistencias — como es bien sabido- procedentes de discriminaciones racistas o prejuicios étnicos. Y éstos no siempre tienen un origen ajeno o lejano. Como Norbert Elias hizo notar (Establecidos y forasteros, 1965$)^{3}$, incluso entre británicos del área metropolitana de Leicester, se apreciaba un claro sentido de superioridad de los residentes allí desde hacía medio siglo respecto a los recién llegados. A los que se excluía y rechazaba como advenedizos, atribuyéndoles una larga serie de rasgos negativos que los estigmatizaban, cuando en realidad la única diferencia que los separaba era el momento de su asentamiento en la zona. Los viejos residentes se autoatribuían un carisma grupal superior que, a la inversa, se convertía a sus ojos para los forasteros — tan británicos como ellos- en una supuesta extrema ignorancia, indisciplina e inmoralidad, que en realidad poco tenían que ver con los hechos.

\footnotetext{
2 Como se señala al respecto, «entre los más básicos móviles de la emigración, se encuentra el prestigio relativo, tan importante como la seguridad o la estabilidad económica» (p. 43).

${ }^{3}$ La xenofobia implica una posición previa de superioridad que no necesariamente se basa —como ocurre en este caso- en diferencias étnicas, nacionales, raciales, etc., contra lo que algunos creen, sino de clase social, apoyadas en ciertos prejuicios «justificativos».
} 
Contemplando el problema de la incomprensión de las necesidades de otros, y su habitual consecuencia de la discriminación, es preciso hoy referirse a colectivos mucho mayores y, por tanto, contemplar las dos caras del problema. Así, es frecuente en los países menos desarrollados culpar a las antiguas potencias coloniales de su atraso económico y técnico, con las consabidas consecuencias de frustración y bajos ingresos de la mayoría. Esto es evidente; pero tal situación también suele coincidir con una altísima responsabilidad —casi nunca reconocida- en las elites y grupos económicos privilegiados responsables del desarrollo de tales países, que o explotan sin escrúpulos a la mayoría de la población o, al menos, no se esfuerzan lo suficiente por disminuir las desigualdades sociales.

De una u otra manera, el mandamiento de ayuda al prójimo se halla en varias religiones, especialmente en la cristiana. Y en cuanto al Islam, el precepto de actuar con caridad para con otras personas constituye uno de sus cinco preceptos básicos (según se deduce en particular de la sura 2 del Corán, en su extenso versículo 263, entre otras) ${ }^{4}$. Pues bien, el hecho es que la mayoría de los países de creencia musulmana mayoritaria se encuentran en muy bajos niveles de ingresos por cabeza, en contraste con un escaso número de ellos, los llamados «petrolíferos», que los superan en tales ingresos en más de veinte veces per cápita (lo que coincide, por ejemplo, con la «distancia» existente en 2001 entre Arabia Saudí y Pakistán, por no citar otros casos aún más extremos). Cabe preguntarse hasta qué punto los más favorecidos de las comunidades musulmanas destinan alguna parte significativa de sus inmensos beneficios a la ayuda de quienes no pocas veces se encuentran en el límite de la supervivencia.

No es menos cierto que, aparte los petrolíferos, la práctica totalidad de los países más desarrollados pertenecen al mundo occidental y, a excepción de instituciones privadas como las ONG, escatiman, en forma a menudo visiblemente miope, su solidaridad con los problemas del llamado «tercer mundo».

La identidad y los derechos de ciudadanía son dos elementos indispensables en los sistemas políticos modernos, pero no siempre se encuentran coordinados. Cada vez con mayor frecuencia, los derechos se definen a nivel global, en base a principios universalistas, de uniformidad jurídica y abstracción. Por el contrario, las identidades todavía parten del particularismo y de una determinada vinculación territorial. Se hace preciso compaginar ambos elementos en los Estados con fuerte inmigración, de una forma equilibrada que no lesione ni derechos ni aspiraciones de ciudadanos y residentes. Lo cual, evidentemente, es un tema tan vivo como difícil. A ello contribuye la situación de inferioridad económica de centenares de millones de habitantes de países poco desarrollados. Dicho de otro modo, las

${ }^{4}$ El versículo coránico no se limita a aconsejar la limosna como mérito ante Dios, sino como obligación de los creyentes. 
fuerzas del mercado incitan hacia la emigración a millones de personas, pero a la vez los intereses políticos que dirigen los países más poderosos procuran reducir $\mathrm{y}$, desde luego, controlar tales movimientos. Lo cual desemboca a menudo en políticas vacilantes, que de golpe cortan las facilidades de inmigración o bien abren inesperadamente una cascada de inmigrantes sin cualificación o, incluso, casi indocumentados. Un claro ejemplo de esta política se ha presenciado en estos últimos años en España, por citar un solo caso.

Tal vez se comprenda mejor la situación internacional a este respecto si observamos la fuerte influencia que en ella tiene la extrema desigualdad de los países en cuanto a sus respectivas distribuciones de la renta. En un reciente trabajo (J. Cazorla, 2002) ofrecíamos datos según los cuales la diferencia entre los ingresos por persona de los 19 países más desarrollados (con 800 millones de habitantes) y los 33 más pobres del planeta (con casi 2.000 millones), tan sólo en las dos últimas décadas, había aumentado mucho. Hasta el punto de que si en 1980 era preciso sumar los ingresos de 42 habitantes «pobres» para igualar los de uno sólo de los «ricos», en 2001 se hacía necesario acumular los de 63 de los menos desarrollados, e incluso de 107 subsaharianos, que se encontraban en la peor situación, para conseguir tal igualación. De manera que la distancia entre ambos grupos de países no sólo no se está acortando, sino que se incrementa cada día. En ese día y los siguientes, los ingresos de cientos de millones de personas no superan más de un dólar per cápita. Con un hipócrita eufemismo, se dice que son países «en vías de desarrollo». Pero no son vías convergentes, sino cada vez más separadas y divergentes.

Esta penosa desigualdad hace que — con una visión algo simplista - se responsabilice por un considerable bloque de población, predominantemente musulmana, al mundo occidental del atraso económico que padece y de sus consiguientes dificultades de toda índole. Sin excluir la parte de culpa que las antiguas potencias coloniales y ciertas grandes empresas multinacionales puedan tener en tales dificultades, no es menos cierto que la responsabilidad de muchas de las lamentables situaciones de hambre, epidemias y miseria de numerosos países que a diario vemos en los medios es resultado de la corrupción y prácticas habituales de sus propias minorías dirigentes. $Y$ no menos de sus feroces luchas intestinas y también mutuas — sobre todo desde 1945-, de la radicalización ideológica de diversas facciones, de la explotación sistemática de los sectores menos pudientes, del vertiginoso crecimiento demográfico y del interesado victimismo que sirve de tapadera a tantos abusos. En un conocido libro, Huntington ha asegurado en concreto que, desde los años noventa, "de dos terceras a tres cuartas partes de las guerras entre civilizaciones han sido entre musulmanes y no musulmanes", lo que atribuye a la intransigencia y exclusivismo del Islam, que califica de «obstáculos» a la adopción en estos países de medidas democráticas. Según este punto de vista, la identidad y las creencias islámicas se antepo- 
nen a las lealtades e ideas occidentales basadas en la nación o el Estado, o a nuestra noción del individualismo, enfrentada a su vez con la umma musulmana.

Es un hecho próximo a nosotros que la rica herencia histórica y artística árabe que se recibió, sobre todo en Andalucía (y más en concreto en Córdoba y Granada), no debe ser utilizada válidamente para depreciar la no menos valiosa castellana, que ha moldeado nuestra identidad al menos en los cinco últimos siglos. La cual, unida al conjunto de las variedades culturales de los pueblos de España, se empieza a integrar hoy en un bloque europeo de naciones cada vez más sólido e inevitable.

Por otra parte, y continuando con la referencia a la situación de los países con predominio musulmán, existe entre los comentaristas bastante acuerdo en el sentido de que en ellos se está produciendo una cierta modernización y tendencia a la reforma, favorable a la separación entre la mezquita y el Estado. Más aún, según estudios de Rose, dentro de todos los grupos religiosos, una mayoría cree que la democracia es mejor que cualquier otra forma de gobierno. Sin embargo, los autores árabes del Arab Human Development Report (2002) reconocen también que la oleada global de democratización «apenas alcanzó a los Estados árabes. Este déficit de libertad socava el desarrollo humano y ralentiza el desarrollo político». Y añade: «No puede haber ninguna posibilidad de reforma del sistema de gobierno... si no existe una representación política completa en asambleas legislativas efectivas basadas en elecciones libres, honestas, eficientes y periódicas». Es también un hecho que varios regímenes islámicos han utilizado el conflicto árabe-israelí para distraer la atención pública y reforzar el apoyo a su propio gobierno autocrático (Diamond, 2003) 5 . Hablando en términos más generales, es bien claro que el desarrollo económico de diversos países se ha visto acompañado de cambios sociales, culturales y económicos que, a su vez, han propiciado transiciones hacia la democracia. El caso de España es ya clásico, así como Grecia y Portugal, pero más recientemente se aprecia cómo Taiwan o Corea del Sur siguen caminos hasta cierto punto similares, al igual que países de Centro y Suramérica. En el año 2000, 106 Estados, reunidos en una Conferencia denominada «Hacia una Comunidad de Democracias», acordaron «respetar y defender una lista detallada de principios y prácticas fundamentales, garantizadas por un poder judicial independiente, la libertad de asociación y de organización de partidos políticos». Es decir, hay un claro movimiento hacia una garantía global de democracia constitucional (Diamond, ibid.). Sin embargo, se dan ciertos vaivenes en la apertura democrática, que a menudo son resultado de que las expectativas que tal apertura suscitó no se materialicen con la rapidez que sería de desear. Tal es el caso de la antigua Alemania Oriental o incluso de la propia Rusia. Por

5 Según Diamond, «la mayoría de las regiones que (en el mundo) habían sido bastiones del autoritarismo, han visto mejorar en al menos un punto su nivel de libertad en el índice combinado de siete puntos (en Asia fue sólo medio punto). En Oriente Medio sin embargo, el nivel medio de libertad ha disminuido en al menos medio punto» (p. 20). 
el lado contrario, y tres lustros después de la desaparición de la mayoría de los regímenes comunistas, no se percibe en el horizonte ninguna otra nueva ideología de izquierda que pudiera dar origen a una aceptación capaz de competir con ella.

Los regímenes dictatoriales que quedan subsisten sobre bases tradicionales (como algunos árabes), de descomposición política de origen tribal (como varios africanos) o bajo estructuras militaristas de corto alcance temporal, cuyo fin es fácilmente predecible. Si bien pueden no estar preparados para mantener un autogobierno responsable, es evidente que la mayoría de su población aspira a gozar de mayor libertad, participación en los asuntos públicos y acabar con la corrupción. En la medida en que esta población consiga generalizar sus expectativas y promover iniciativas privadas que permitan crear una Administración pública responsable y estable, las Fuerzas Armadas y policíacas no serán ya el único soporte del poder, sino el consentimiento y el convencimiento de la población respecto a la validez, representatividad y legitimidad de sus líderes políticos.

Uno de los más profundos cambios que, a pesar de la oposición de ciertos gobiernos, se está produciendo en todo el mundo es, como decimos, la creciente aspiración de millones de personas desfavorecidas a participar, en la medida de lo posible, de la prosperidad de los países más desarrollados. Las vacilaciones de los dirigentes políticos de éstos derivan de la dificultad para mantener una situación etnoeconómica imposible de recuperar, y la ansiedad resultante de la previsión de un futuro, no muy lejano, con una población cuya composición es ya —o dentro de poco va a ser-muy diferente de la que ha persistido durante siglos. Desde luego, no todos los países participarán de este cambio, como algunos (casos de Rusia y China) que recibirán muy escasos inmigrantes.

Entre los rasgos más perceptibles y característicos de los flujos migratorios actuales están, en resumidas cuentas, los de globalidad, ya comentada; espontaneidad, con su frecuente secuela de clandestinidad; diversificación amplísima a centenares de etnias; permanencia (o sea, continuidad a largo plazo); asentamiento en destino, en lugar de migraciones «golondrina»; retorno a localidades de origen tan sólo vacacional y muy breve; acomodación, pero no absorción, y visibilidad, tanto por su exteriorización como por su diferenciación externa y, sobre todo, por su volumen.

En el aspecto sobre todo de la acomodación, los inmigrantes interpretan según sus vivencias previas el nuevo sistema social al que se incorporan. De forma que se resocializan, modificando una serie de conductas e incluso valores y creencias. Buscan un cierto refugio psicológico en la protección del colectivo a que pertenecen, a la vez que contribuyen a la construcción de una nueva identidad común, basada en unos intereses también comunes. Su fin último es el reconocimiento por parte de la sociedad de acogida, evitando la asimila- 
ción o absorción sin más. A través de tal reconocimiento de su diversidad, pueden conservar buena parte de los rasgos de su cultura de origen y, a la vez, su equiparación en la de acogida como actores sociales, con identidad propia, y reconocidos como miembros del sistema (Del Olmo, 2003) .

Contemplando ahora el futuro de la Unión Europea en particular, estimaciones muy solventes advierten que para mantener el número de personas activas laboralmente que había en 1995, en 2025 habrá sido necesario admitir en la UE un mínimo de 24 millones de inmigrantes. De manera que la acomodación de que hablamos va a ser un fenómeno de gran importancia inmediata. En este mismo sentido, parece lógico concretarnos ahora al caso específico de España, país que — con mayor razón en nuestra propia costa andaluzaestá sirviendo como «frontera sur» ante el acceso de una creciente oleada inmigratoria, legal o bien indocumentada.

\section{INMIGRACIÓN EN ESPAÑA}

Como se ha hecho notar a menudo, en un brusco cambio histórico, España ha pasado en poco más de una década de ser país de emigración a país de inmigración. Este cambio se ha acentuado especialmente con la entrada inesperada, desde mediados de los años noventa, de un volumen de inmigrantes laborales (es decir, excluidos turistas, hombres de negocios, profesionales y similares) que ya supera los tres millones. A partir del año 2000, la situación exigió la urgente actualización de la Ley de Extranjería de 1985, promulgándose una nueva en 2000 y modificándola tres veces más desde aquel momento. Como hemos señalado, sólo en una región, Andalucía, limítrofe con el tercer mundo (a tan sólo 14 kilómetros de distancia en el estrecho de Gibraltar), en los años 2004 y 2005 la entrada por la costa de inmigrantes sin documentación ha sido constante, y su expulsión, inmediata (se calcula en unos 12.000 en 2004). Un simple ejemplo permite obtener una idea del impacto sin precedentes que este movimiento demográfico produce en una sociedad -la nuestra- que posee una de las tasas de natalidad más bajas del mundo; según noticias de prensa, en los últimos seis meses de 2004 , un número desproporcionadamente alto de niños nacidos en España eran hijos de inmigrantes.

Se ha calculado que, desde 2003, España constituye el destino más preferente de todos los inmigrantes que entran en la UE: casi uno de cada cuatro de ellos (23\%) opta por este país. La estimación para el año 2010 es que habrá aquí unos seis millones permanentes

6 Dice textualmente Del Olmo: «... una persona se identifica con otra cuando ambas han estado (o están) afectadas por los mismos hechos» (p. 34). 
(predicción que muy probablemente va a quedar corta), y para el 2015 serán casi doce millones. Un Informe del Banco de España (agosto de 2004), apoyado en estimaciones del Instituto Nacional de Estadística, prevé que la población total española crecerá -incluida la aportación de los inmigrantes - hasta el año 2050, llegando a los 53 millones de habitantes, para comenzar a disminuir a partir de aquel momento, debido al envejecimiento del conjunto (la tasa de dependencia pasará del $25 \%$ en 2005 al $56 \%$ en 2050).

Respecto al número de quienes no poseen permiso de residencia, actualmente viene a ser de 1.200.000, contando sólo los de origen hispanoamericano o africano. La casi totalidad de los que entran como turistas de estos y otros orígenes (asiáticos, filipinos o del Este de Europa) se quedan en España, una vez caducado el permiso de entrada por tres meses de que disponen. Por ejemplo, se sabe que en 2002 salió menos del 1\% de los ecuatorianos que habían entrado (unos 130.000). Precisamente son estos y los marroquíes quienes aportan el mayor número de inmigrantes por nacionalidades. Más o menos un $15 \%$ del total de extranjeros que aquí trabajan pertenecen, respectivamente, a Ecuador y otros tantos a Marruecos (Cea D’Ancona, 2004).

Un factor novedoso en el estímulo de las migraciones es la presencia de organizaciones mafiosas que rentabilizan las modernas facilidades de transporte, utilizándose redes de conexiones personales para ayudar y fomentar los movimientos clandestinos. En el Mediterráneo occidental tenemos un constante ejemplo de esta situación. Ciertos gobiernos llegan incluso a favorecer o impulsar más o menos ocultamente la emigración de sus propios ciudadanos (muchos de ellos en paro permanente), ya que no sólo alivian la presión -laboral y también política- del desempleo, sino que además les aportan de inmediato un importante aflujo de divisas. En definitiva, el que un apreciable número de extranjeros entre en la Unión Europea por vía aérea como falsos turistas, incluso desde países tan lejanos como China o Filipinas, o crucen el Mediterráneo como supuestos pescadores, no son más que dos ejemplos de la variedad de posibilidades que actualmente se abren a los movimientos colectivos de población, por vía legal o ilegal ${ }^{7}$.

El rápido crecimiento de la población inmigrante en España, que comentamos, ha provocado reacciones no muy diferentes de las que se han registrado en otros países europeos. Así, ha crecido el número de personas que muestran diversos grados de intolerancia respecto a los inmigrantes laborales; por ejemplo, comentando que no deben mantener sus costumbres y, en cambio, adaptarse a las españolas. Los sectores que menos propicios se manifiestan al respecto suelen ser las personas de mayor edad, menor nivel de estudios,

7 Como referencia más reciente, en la regularización de inmigrantes abierta por el Gobierno, a comienzos de mayo de 2005 , se habían inscrito y aceptado definitivamente casi 700.000 de ellos, hasta ese momento en situación no legal. 
mayor inclinación a ideologías de derecha y radicalismo religioso, y habitantes de localidades más pequeñas. Salvo en una pequeña minoría, no se aprecia un rechazo a la entrada como tal de los inmigrantes, sino hacia quienes lo hacen careciendo de contrato de trabajo. No obstante, casi la mitad de los encuestados al respecto opina que «ya son demasiados». En cuya actitud influye, sin duda, la acumulación repentina que se ha producido en estos últimos años, y que ya hemos comentado.

No es menos cierto que las actitudes abiertamente racistas sólo son expresadas por minorías bien identificadas; pero también, de una forma no muy explícita, un número muy considerable de personas sigue sintiéndose reticente ante los inmigrantes o aceptando alguna forma de racismo. Es también evidente que se admite con preferencia a los inmigrantes laborales del Este, a menudo con conocimientos de idiomas y educación relativamente altos, antes que a los latinoamericanos, aunque compartamos lengua y abundantes bases culturales, quedando en último lugar los marroquíes y subsaharianos, que percibimos como más «diferentes», y que por tanto producen mayor grado de «prevención». Hay, por tanto, ya una diversidad de perspectivas en cuanto al extranjero, muy distinta de la existente hasta hace poco.

Cabe decir que todavía muchos tienen una cierta visión negativa del «no español», como alguien que no comparte buena parte de nuestras creencias, símbolos, tradiciones y hábitos; alguien «diferente», en suma. Pero a la vez, al surgir la ciudadanía europea, se están forjando una serie de lazos con otros pueblos de Europa que matizan esta percepción, de tal modo que con el tiempo se llegue a fundir el concepto de cada nacionalidad con el de ciudadano de la Unión Europea. De manera que en el próximo horizonte aparecen en nuestra opinión pública tres nociones simultáneas: la de compatriota español, la de ciudadano europeo y la de extranjero, ésta con sus subclases de diferentes inmigrantes. Es con ellos -especialmente los de procedencia magrebí, como hemos señalado- con quienes se percibe una distancia mayor, a pesar de que la geográfica es precisamente la menor. Por supuesto, cuando se trata de magrebíes de nivel económico y educativo medio a alto la «distancia» se reduce proporcionalmente, e incluso se produce a la inversa en el caso de personajes o potentados árabes. Pero no está de más recordar que una larga experiencia histórica compartida ha tendido tanto a separarnos como a unirnos.

Es preciso mencionar entre las causas que contribuyen a ciertas incomprensiones un reciente acontecimiento histórico peculiar: los atentados terroristas que en Madrid produjeron 192 muertos el 11 de marzo de 2004, sin precedentes en Europa, y que influyeron en cierto modo en el reforzamiento de un clima de desconfianza no respecto a los inmigrantes en cuanto tales, sino a los de origen islámico. También debe recordarse que desde el 2000 se ha detenido y procesado en España con acusaciones de terrorismo a más de 330 inmi- 
grantes precisamente de ese origen, por lo que no puede negarse que el referido clima podría poseer cierto fundamento.

Aun dejando a un lado tales sospechas — que en modo alguno pueden generalizarse-, es un hecho la cotidiana aparición en los medios de comunicación de noticias sobre el desembarco de inmigrantes magrebíes con medios muy precarios en nuestra costa sur y en Canarias. Ello ha fomentado una imagen parcial, conflictiva y, en cierto modo, molesta de estas gentes, que en realidad se juegan la vida en el peligroso trayecto del Mediterráneo o el Atlántico, en busca de una estabilidad laboral y económica que nunca podrán alcanzar en sus países. Las insalvables desigualdades sociales de éstos, de origen demográfico pero también sociopolítico, destruyen cualquier esperanza — sobre todo en los jóvenesde mejora en un futuro previsible, por lo que, por miles, se lanzan a la aventura de alcanzar una Europa tan próxima como mitificada. Otro tanto ocurre con muchos subsaharianos.

Encuestas realizadas en los últimos años demuestran un aumento del rechazo y la intolerancia cultural en España, aunque no en proporciones diferentes de las de otros países europeos de anterior tradición multicultural. Se observa bastante anuencia de los encuestados a la hipótesis del cobro de subsidios por el inmigrante, en caso de que se quede en paro, o a que al cabo de algún tiempo adquiera la nacionalidad española. En cambio, es mayor el número de los que se oponen a que pueda votar en las elecciones municipales o generales (CIS, 2000 a 2003). En cambio, en algunos países de la UE, los inmigrantes gozan ya de ciertos derechos políticos. Así, en Bruselas, el 14\% de los concejales electos fue en 2000 de origen extracomunitario. En términos generales, estudios de 2003 (Cea, cit.) dan una proporción del 38\% de los españoles encuestados como «tolerantes», favorables a la inmigración; otro $32 \%$ «ambivalentes», con cambios de opinión según las circunstancias, y «reacios», predispuestos a rechazarla, el restante $30 \%$.

Con todo, debe quedar claro que una inmigración bien organizada difícilmente perjudica al país de acogida, sino que le beneficia, al incorporarse gente en la plenitud de su capacidad de producción. Es decir, su economía consigue una plusvalía que de otro modo no hubiera obtenido. Cuestión distinta es que, en los países más desarrollados, cada vez es menos necesaria la mano de obra sin cualificación alguna, hoy sustituible en buena parte por los avances de la tecnología.

Por otro lado, una de las situaciones que mayor rechazo provocan en destino es la de aquellos inmigrantes que se ocultan y permanecen en la economía sumergida, desempeñando trabajos que se supone «no les son propios», es decir, en los que compiten con los locales. Si además cobran menos por realizarlos, la reacción puede llegar a ser de inmediata hostilidad en quienes los acusan de competencia ilegal. En tal circunstancia o simila- 
res se vuelve a la percepción que los burgueses de hace un siglo tenían de los obreros: al estigmatizarlos como seres amorales, podían cargarse de razón, subjetivizando el conflicto y eludiendo a la vez sus implicaciones políticas y económicas. Es decir, a menudo se mezclan actitudes de discriminación de clase con las de marginación étnica o racial, a las que encubren.

Más en general, es claro que en nuestra sociedad el componente más importante del estatus es el económico, derivado del laboral-profesional. Pero un apreciable número de inmigrantes se ve forzado a ocupar cuando llega una posición que considera inferior a la que, según su propia cultura de clase, le correspondería (por no reconocimiento aquí de títulos profesionales o nivel educativo, o incluso por prestigio familiar o étnico, etc.). Con lo cual sufre una degradación de estatus que significa una permanente situación de incomodidad emocional y sufrimiento. A muchos, la mera calificación de «africano» (como ocurre con los marroquíes), o no digamos de «tercermundista», les suena directamente como insulto. Lo cual no siempre parte de un propósito de denigración en quien los usa. Pero cuando las diferencias aparentes (como el aspecto físico) son menores, el concepto de «extranjero», en lugar del de «inmigrante», suele ser más satisfactorio. En este ámbito, como ya hemos comentado, los europeos del Este tienen clara ventaja y, por tanto, pueden adaptarse a su nuevo ambiente con más facilidad. En resumidas cuentas, a lo largo del próximo tercio de siglo, la UE, y España en particular, van a necesitar la entrada de varios millones de inmigrantes, pero no el acceso indiscriminado de cualesquiera personas, con cualesquiera conocimientos y en cualquier cantidad.

Pasando ahora al ámbito económico internacional, y en términos más generales, tampoco las ayudas internacionales al desarrollo ni los préstamos del Banco Mundial e instituciones similares son suficientes $\mathrm{ni}$ - a menudo- son capaces de sobrepasar las fuertes desigualdades entre países, enraizadas en estructuras de poder tradicionales, que se resisten a cualquier cambio. Más aún, dichas ayudas están lejos de la meta oficial del 0,7\% del PIB que se propusieron hace una década los países de la OCDE: por el contrario, tal porcentaje ha disminuido en dicho período desde el 0,36 al 0,24\%. En España sólo se alcanzó en 1999 el 0,23\%, y podría haberse llegado en 2004 al 0,39\%, todo lo más.

Tras esas diferencias y las demás internacionales que mencionábamos antes hay en juego poderosos intereses que operan con las diferencias no sólo entre las «ayudas», sino más a fondo entre conceptos como multiculturalismo e interculturalismo. La práctica ha demostrado que aquél conduce al apartheid, mientras que la educación en éste es un proyecto de convivencia, un diálogo en plano de igualdad, una política realista, a partir de consensos 
reconocidos y exigibles, sobre un entendimiento mutuo y un reconocimiento de diferencias aceptables que sólo excluyen precisamente la intolerancia.

No se debe seguir el camino de la confrontación ni la incomprensión; es preciso no confundir variedades culturales como el Islam con las interpretaciones que, en un momento dado, sectores más o menos radicales nos den interesadamente de sus doctrinas. También formas de integrismo que rechazan la civilización occidental - y que no necesariamente coinciden con doctrinas ortodoxas usuales - pueden nacer de las duras condiciones de vida impuestas a grandes masas de población, en cuyo origen los principales responsables pueden ser los dictadores o responsables políticos de esos mismos países.

Si Occidente se decidiera a combatir a esas elites corruptas y facilitara con verdadera eficacia el desarrollo de los recursos propios, y no menos de las personas, mediante la educación, la comprensión de las diferencias culturales, una distribución más equitativa de la riqueza, y formas selectivas de producción apoyadas en una sólida base económica, desaparecerían muchas opresiones y otras tantas radicalizaciones, floreciendo en cambio las más diversas formas culturales y un mejor entendimiento en el plano internacional.

\section{BIBLIOGRAFÍA}

ABAD MÁRQUEZ, L. V. (2002): «Contradicciones de la globalización: migraciones y convivencia interétnica tras el 11 de septiembre», en Revista Migraciones, n. ${ }^{\circ} 11$, junio.

BOYD-BARRET, O. (1999): «Trends in World Communication», en Global Dialogue, n. ${ }^{1}$, pp. 56 y ss.

BARBADILLO GRIÑÁN, P (1997): Extranjería, racismo y xenofobia en la España contemporánea, CIS-Siglo XXI, Madrid.

BRENAN, G. (1963): South from Granada, Penguin, p. 222.

CAZORLA PÉREZ, J. (1989): Retorno al Sur, Siglo XXI-OCAER, Madrid.

- (1995): «La inmigración marroquí en España: datos, opiniones y previsiones», en Revista Internacional de Sociología», n. ${ }^{\circ} 12$, septiembre-diciembre, pp. 117 y ss.

- (2002): El dilema Norte-Sur al inicio del siglo XXI, Working Papers n. ${ }^{\circ}$ 199, ICPS, Barcelona.

CEA D'ANCONA, M. ${ }^{a}$ A. (2004): La activación de la xenofobia en España, CIS, Madrid.

CHECA, F. (1995): «Migración, riesgo y beneficios. Los inmigrantes en la provincia de Almería», en Demófilo, Revista de Antropología, n. ${ }^{\circ} 15$, pp. 103 y ss.

CIS (1995): Discursos de los españoles sobre los extranjeros, Opiniones y Actitudes, n. ${ }^{\circ} 8$, Madrid. $^{2}$

- (2004): Opiniones y actitudes de los españoles ante el fenómeno de la inmigración, n. ${ }^{\circ}$ 48, Madrid. 
DEL OLMO, N. (2003): «La construcción de identidades colectivas entre inmigrantes», en REIS, n. ${ }^{\circ} 104$, octubrediciembre.

DIAMOND, L. (2003): «¿Puede el mundo entero ser democrático? Democracia, desarrollo y factores internacionales», en Revista Española de Ciencia Política, n. ${ }^{\circ}$, octubre.

DI COMITE, L., y MORETTI, E. (1999): Geopolítica del Mediterráneo, Carocci, Roma.

ELIAS, N. (2003): «Ensayo teórico de las relaciones entre establecidos y forasteros», reproducido en REIS, $\mathrm{n} .{ }^{\circ} 104$, octubre-diciembre.

GARRETT, G. (2000): Globalization and Government Spending around the World, Working Papers n. ${ }^{\circ} 155$, Instituto $^{2}$ Juan March, Madrid.

GOZÁLVEZ, V. (2000): «Inmigración: causas y perspectivas», en Nueva Revista, n. ${ }^{\circ} 71$, septiembre-octubre.

HUNTINGTON, S. P. (1997): El choque de civilizaciones, Paidós, Barcelona.

JEREZ, A.; SAMPEDRO, V., y BAER, A. (2000): Medios de comunicación, consumo informativo y actitudes políticas en España, Opiniones y Actitudes, $\mathrm{n}^{\circ}{ }^{3}$, $\mathrm{CIS}$, Madrid.

LÓPEZ, B. (coord.) (1993): Inmigración magrebí en España, Mapfre, Madrid.

MARTÍNEZ, M. F., y otros (1996): La integración social de los inmigrantes africanos en Andalucía, Universidad de Sevilla y Junta de Andalucía.

PERES, H. (1999): «L'Europe commence en Gibraltar: le dilemme espagnol face a la decouverte de l'integration», en Pole Sud, n. ${ }^{\circ} 11$, noviembre, pp. 8 y ss.

RAMÍREZ, E. (1996): Inmigrantes en España: vidas y experiencias, CIS, Madrid.

REIG, R. (1998): Medios de comunicación y poder en España, Paidós, Barcelona.

SOLÉ, R., y otros (2000): «El impacto de la inmigración en la sociedad receptora», REIS, n. ${ }^{\circ}$ 90, abril-junio. VALLESPÍN, F. (2000): El futuro de la política, Taurus, Madrid, pp. 28-60.

Key words: Migrations, Globalization, Places of Refuge and Origin, Risks, Traditional Culture, Unemployment, Frustration, Inequalities, Self-assessment, Islamic Regimes, Racism. 